\section{General practitioner hospitals: coming or going?}

Papers in the last four weeks' issues of the $B M \mathcal{F}$ raise again a question which has smouldered since the early 1960 s. At that time the Department of Health's policy favoured the elimination of small, peripheral hospitals and the concentration of acute services in large, central district general hospitals. Opinions on the place of general practitioner hospitals still differ, but these four papers show not only that they are still surviving but also that they can provide a real service to the community and to general hospitals-if they are effectively managed.

Firstly, North and others (21 April, p 1209) described a pioneering 24 bed hospital in a deprived urban area. It has no outpatient or diagnostic facilities and no regular consultant visits but emphasises facilities for rehabilitation and maintenance of patients (especially the elderly) in the community. The authors estimate that almost half the patients would have occupied a bed in a district general hospital had the new hospital not been available, and half would have remained at home. Eighty five per cent were discharged home, mostly in less than one month.

Next, Johnson (28 April,p 1293) described surgical practice in a community hospital in Brecon. Though this hospital is atypical (in that nearly all the general practitioners have hospital specialist qualifications), he described a method of review which could be applied to community hospitals in general-and, implicitly, to major surgical units as well. Some $85 \%$ of all inpatient surgery on Brecon residents is performed in the community hospital; complication rates (such as wound infection and recurrence of hernia) are acceptable, and waiting lists are short. Even with anonymous questionnaires an opinion survey may be biased, but there is a clear message in the finding that of patients who had an operation in Brecon $96 \%$ said they preferred that to surgery in a district general hospital.

Last week ( $p$ 1366) Grant reported on the facilities and distribution of hospitals in Scotland staffed primarily by general practitioners. Most of these are more than 30 miles $(48 \mathrm{~km}$ ) from a district general hospital and have casualty and outpatient clinics. Intrapartum maternity beds are available in almost twice as many hospitals as surgical beds.

The final paper ( $p$ 1438) pursues this theme south of the border, with Cavenagh and others discussing the place of isolated general practitioner maternity units. In 131 units separate from consultant sites the "average" general practitioner has 10 deliveries a year and the "average" midwife has 20 . Nearly $40 \%$ of units have no visiting consultant and $10 \%$ no flying squad cover. Perinatal mortality is predictably low, and the authors suggest that transfers in labour ( $8 \%$ of all bookings in the survey) are a better index of a unit's success or failure: they reflect the adequacy of the selection process-which is "clearly capable of further refinement."

These four papers support the view that general practitioners should care for their own patients in hospital, but among both patients and staff opinions differ on what constitutes a "good" service. Patients give priority to ease of access, comfort, and the reassurance of familiar surroundings; to obtain these they are often willing to forego the virtues (usually unmeasurable) of technical excellence. Indeed, much of the debate among clinicians concerns relative safetyespecially of acute services such as maternity, surgery, and casualty. Some family doctors appreciate the continuity of care offered by general practitioner beds, and, especially as more principals are completing vocationai training, enjoy the chance to use hospital based skills. Others see the commitment of time as disproportionate to the rewards and believe that hospital work detracts from their task as primary physicians.

As hospital consultants retire they are being replaced by a younger breed weaned on high technology, who may sometimes be less willing to work in peripheral hospitals. And as the workload increases in central hospitals time spent by consultants in travelling becomes increasingly a luxury-even if it is to a friendly little hospital. Health authorities also face a dilemma. The revenue costs of small hospitals are more easily identified than are those of individual units in general hospitals (without specialty costing), and the great temptation is to prune. Another response, however, may be to preserve small hospitals in order to transfer suitable patients to low technology, low cost care: that would make progress towards providing more care for more people in their own community.

Certainly general practitioner hospitals can reduce demands on district general hospitals, but they also generate demands from the community. ${ }^{12}$ Despite being cheaper in terms of unit costs, it is hard to show that they are more economical overall. Better use of them, however, may provide a realistic alternative to the development of expensive new district general hospitals, and districts are being asked by regions and by the DHSS to consider these possibilities. ${ }^{3} 4$

Our four papers suggest that the effectiveness and efficiency of individual general practitioner hospitals depend largely on recognising the limitations of local facilities and staff, critical internal evaluation, cooperation with district general hospitals over planning and selection of cases, and a clearly defined place within the health district. Sadly, very little objective evidence, such as from clinical trials or cost benefit analysis, has been produced to help define that place.

Nevertheless, decisions must soon be made about the future of several hundred such hospitals in Britain. By the end of this summer each health authority should be finalising its strategic plans for the next 10 years. They should consider carefully the economic and clinical potential of general practitioner hospitals, given a clear purpose and clear management.

Specialist in Community Medicine,

Charles D Shaw

Cheltenham and District Health Authority,

Cheltenham GL50 2QN

${ }^{1}$ Goldacre MJ, Gatherer A. Peripheral outpatient clinics: use, costs and benefits. British fournal of Preventive and Social Medicine $1977 ; 31: 205-8$.

2 Sichel GRM, Hall DJ. A study of six general practitioner hospitals in Tunbridge Wells Health District. Health Trends 1982;14:24-6.

${ }^{3}$ Department of Health and Social Security. The future pattern of hospital provision in England-a consultation paper. London: DHSS, 1980.

4 Department of Health and Social Security. Care in action. London: HMSO, 1981.

\section{Neuroleptic malignant syndrome}

The neuroleptic malignant syndrome of Delay and Deniker is "the most serious but also the rarest and least known of the complications of neuroleptic chemotherapy"; its cardinal features are hyperpyrexia and rigidity. ${ }^{1}$ The syndrome was first described under the name syndrome malin in a French journal $^{23}$; since then isolated reports have been made from many parts of the world ${ }^{4-7}$-but a review in 1980 of over 60 cases $^{8}$ included only one from Britain. ${ }^{9} \mathrm{~A}$ recent report of a 
further case in the $B M \mathcal{F}^{10}$ evoked some correspondence, reflecting an increased interest in the syndrome. ${ }^{11-13}$

The syndrome always develops in close association with treatment with neuroleptic drugs, often early on but sometimes only after several months. The drugs most often responsible have been haloperidol and fluphenazine, but a few cases have been reported with chlorpromazine, thiothixene, thioridazine, trimeprazine, trifluoperazine, and prochlorperazine. ${ }^{14}$ The syndrome has also been reported with tetrabenazine, a catecholamine depleting agent, ${ }^{15}$ and after treatment with levodopa has been stopped. ${ }^{16}$ If the patient recovers reintroduction of neuroleptic treatment does not usually result in reappearance of the syndrome.

The symptoms fall into two main groups, motor (catatonic and extrapyramidal) and autonomic. The catatonic symptoms seem to appear earliest; they are not invariable but may be prominent. $^{56}$ They include withdrawal, hypoactivity developing into akinesia and mutism, and eventually stupor or coma; catalepsy and waxy flexibility may also be seen. The level of consciousness often fluctuates between alertness and clouding. The extrapyramidal symptoms consist of akinesia (difficult to differentiate from catatonia) and rigidity of the lead pipe type, which may increase into opisthotonos. Involuntary movements such as tremor, chorea, and oculogyric crisis may also occur. The change in muscle tone in the oropharyngeal muscles may cause dysphagia and dysarthria, and the rigidity of the muscles of the chest wall may cause dyspnoea.

The most important of the autonomic symptoms is hyperpyrexia, which usually develops after the motor symptoms. Its appearance is usually accompanied by autonomic disturbances: cardiovascular disorders (fluctuating blood pressure, tachycardia, peripheral vasoconstriction resulting in pallor); respiratory disorder (dyspnoea); excessive perspiration and sialorrhoea; urinary disorders (dysuria, incontinence); and trophic disorders (sudden development of decubitus).

The full blown syndrome develops fast, usually in 24 to 72 hours. Complications are common; they include thromboembolism, aspiration pneumonia, tachypnoeic hypoventilation from decreased chest wall compliance, cardiovascular collapse, and renal failure. ${ }^{14}$ The mortality is high: in the 60 cases reviewed by Caroff, 12 patients died. ${ }^{8}$ Most patients recover fully within five to 10 days after the discontinuation of the neuroleptic drug, but permanent brain damage has been reported in some patients who had been treated with a combination of haloperidol and lithium. ${ }^{17}$

In the differential diagnosis several conditions must be considered. Catatonia may be difficult to distinguish in some cases, ${ }^{5}$ especially before the full blown syndrome develops. Several authors have likened the neuroleptic malignant syndrome to Stauder's "lethal catatonia," which is not related to neuroleptics and is characterised by extreme psychomotor agitation followed by stupor, coma, rigidity, hyperpyrexia, and death. ${ }^{18}$ Fever and extrapyramidal symptoms may lead to the diagnosis of encephalitis, but the cerebrospinal fluid is normal in the neuroleptic syndrome. The extreme rigidity may suggest tetanus. Hyperpyrexia might develop in patients taking neuroleptics and lead to heat stroke; usually, however, there are no motor abnormalities in this condition. The hyperpyrexia of the neuroleptic syndrome also resembles that seen in malignant hyperthermia associated with anaesthesia; in both conditions there is fever and muscular rigidity. ${ }^{14}$

The pathogenesis of the neuroleptic malignant syndrome is not clear. The drugs seem to be a necessary but not a sufficient condition. The syndrome may possibly result from excessive dopamine receptor blockade in the basal ganglia, ${ }^{15}$ which causes extrapyramidal symptoms, ${ }^{19}$ and in the hypothalamus, where dopamine receptors are concerned in thermoregulation and other autonomic functions. ${ }^{14}$ The catatonic symptoms might also be attributed to dopamine receptor blockade. Neuroleptics cause catalepsy in animals, ${ }^{20}$ and this effect has been ascribed to the blockade of central dopamine receptors. ${ }^{21}$ Catatonia alone is a recognised adverse effect of neuroleptic medication, ${ }^{22}$ and this might be a forme fruste of the malignant syndrome: the full blown syndrome may develop as the dopamine receptor blockade extends to wide areas of the basal ganglia and the hypothalamus. Concurrent administration of lithium with a potent neuroleptic may facilitate the development of a similar malignant syndrome, which may be due to the effect of lithium on dopamine receptors. ${ }^{17}$ When dopamine receptors are exposed to a neuroleptic, a compensatory proliferation ("supersensitivity") of the receptors occurs ${ }^{19}$; this adaptation to the presence of the receptor blocker is inhibited by lithium, ${ }^{23}$ thus presumably resulting in the accentuation of the consequence of dopamine receptor blockade.

There is no specific treatment. The crucial step is to stop the offending neuroleptic immediately. The hyperpyrexia should be treated by cooling, the fluid imbalance rectified by intravenous fluids, and the complications treated as they arise. The muscle rigidity may respond to benzodiazepines, ${ }^{14}$ and there may be a place for dantrolene, a drug effective in relieving rigidity in malignant hyperthermia. ${ }^{13}$

Reader in Psychiatry, University of Manchester,

E SZABADI

Withington Hospital,

Manchester M20 8LR

${ }^{1}$ Delay J, Deniker P. Drug-induced extrapyramidal syndromes. In: Vinken PJ, Bruyn GW, eds. Handbook of clinical neurology. Vol 6. Amsterdam: North Holland, 1968:248-66.

2 Delay J, Pichot P, Lemperiere T, Elissalde B, Peigre F. Un neuroleptique majeur non phenothiazinique et non reserpinique l'haloperidol dans le traitement des psychoses. Ann Med Psychol (Paris) 1960;118:145-52.

${ }^{3}$ Bourgeois M, Tignol J, Henry P. Syndromes malins et morts subites au cours des traitements par neuroleptiques simples et retard. Ann Med Psychol (Paris) 1971;129:729-46.

${ }^{4}$ Meltzer HY. Rigidity, hyperpyrexia and coma following fluphenazine enanthate. Psychopharmacology 1973;29:337-46.

5 Weinberger DR, Kelly MJ. Catatonia and malignant syndrome: a possible complication of neuroleptic administration. Report of a case involving haloperidol. I Nerv Ment Dis 1977;165:263-8.

${ }^{6}$ Itoh H, Ohtsuka N, Ogita K, Yagi G, Miura S, Koga Y. Malignant neuroleptic syndrome-its present status in Japan and clinical problems. Folia Psychiatr Neurol fpn 1977;31:559-76.

${ }^{7}$ Singh G. The malignant neuroleptic syndrome (a review with report of three cases). Indian $\mathcal{f}$ Psychiatry $1981 ; 23: 179-83$.

${ }^{8}$ Caroff SN. The neuroleptic malignant syndrome. 7 Clin Psychiatry $1980 ; 41: 79-83$.

9 Allan RN, White HC. Side effects of parenteral long-acting phenothiazines. Br Med f $1972 ; \mathrm{i}: 221$.

${ }^{10}$ Cope RV, Gregg EM. Neuroleptic malignant syndrome. Br Med $\mathcal{f} 1983$; 286:1938.

${ }^{11}$ Clough CG. Neuroleptic malignant syndrome. Br Med 7 1983;287:128-9.

12 Singh AN. Neuroleptic malignant syndrome. Br Med f 1983;287:129.

13 Cameron AE, Borthwick JM. Neuroleptic malignant syndrome. $\mathrm{Br} \mathrm{Med} \mathfrak{F}$ $1983 ; 287: 129$.

14 Smego RA Jr, Durack DT. The neuroleptic malignant syndrome. Arch Intern Med 1982;142:1183-5.

${ }^{15}$ Burke RE, Fahn S, Mayeux R, Weinberg H, Louis K, Willner JH. Neuroleptic malignant syndrome caused by dopamine-depleting drugs in a patient with Huntington disease. Neurology $(N Y)$ 1981;31:1022-6.

${ }^{16}$ Henderson VW, Wooten GF. Neuroleptic malignant syndrome: a pathogenetic role for dopamine receptor blockade? Neurology $(N Y)$ 1981; $31: 132-7$.

${ }^{17}$ Cohen WJ, Cohen NH. Lithium carbonate, haloperidol, and irreversible brain damage. $7 A M A 1974 ; 230: 1283-7$.

18 Stauder KH. Die tödliche katatonie. Arch Psychiatr Nervenkr 1934;102: 614-34.

${ }^{19}$ Marsden CD, Jenner $P$. The pathophysiology of extrapyramidal sideeffects of neuroleptic drugs. Psychol Med 1980;10:55-72.

${ }^{20}$ Stille G. Zur pharmakologie katatonigener Stoffe. 5. Die wirkung von neuroleptica. Arzneimittelforsch 1971;21:800-8.

${ }^{21}$ Sanberg PR. Haloperidol-induced catalepsy is mediated by postsynaptic dopamine receptors. Nature $1980 ; 284: 472-3$.

${ }^{22}$ Cremona-Barbaro A. Neuroleptic-induced catatonic symptoms. $\mathrm{Br} \mathcal{F}$ Psychiatry 1983;142:98-9.

${ }^{23}$ Bunney WE Jr, Garland BL. Possible receptor effects of chronic lithium administration. Neuropharmacology 1983;22, suppl:367-72. 